University of Nebraska - Lincoln

DigitalCommons@University of Nebraska - Lincoln

Educational Psychology Papers and

Publications

Educational Psychology, Department of

June 2006

\title{
An Examination of the Efficacy of Conjoint Behavioral Consultation with Diverse Clients
}

\author{
Susan M. Sheridan \\ University of Nebraska-Lincoln, ssheridan2@unl.edu \\ John W. Eagle \\ University of Kansas \\ Elizabeth Doll \\ University of Nebraska-Lincoln, bdoll2@unl.edu
}

Follow this and additional works at: https://digitalcommons.unl.edu/edpsychpapers

Part of the Educational Psychology Commons

Sheridan, Susan M.; Eagle, John W.; and Doll, Elizabeth, "An Examination of the Efficacy of Conjoint Behavioral Consultation with Diverse Clients" (2006). Educational Psychology Papers and Publications.

16.

https://digitalcommons.unl.edu/edpsychpapers/16

This Article is brought to you for free and open access by the Educational Psychology, Department of at DigitalCommons@University of Nebraska - Lincoln. It has been accepted for inclusion in Educational Psychology Papers and Publications by an authorized administrator of DigitalCommons@University of Nebraska - Lincoln. 


\title{
An Examination of the Efficacy of Conjoint Behavioral Consultation with Diverse Clients
}

\author{
Susan M. Sheridan \\ University of Nebraska-Lincoln \\ John W. Eagle \\ University of Kansas \\ Beth Doll \\ University of Nebraska-Lincoln
}

\begin{abstract}
This study explored the efficacy of conjoint behavioral consultation (CBC) by assessing objective outcomes and social validity with a sample of students with and without diversity. Diversity characteristics that were investigated included ethnicity, socioeconomic status, family composition, maternal education level, and language spoken in the home. Behavioral change, goal attainment, acceptability, satisfaction, and perceptions of efficacy of the CBC model were measured with 125 students representing varying levels of diversity, and 192 target behaviors. Data were collected across 8 years of a federally funded training program across two states. Findings indicated that $\mathrm{CBC}$-mediated interventions yielded generally high effect sizes regardless of the presence of diversity or the number of diverse characteristics exhibited. Social validity measures also yielded very favorable results, suggesting that participants (teachers and family members, including those who experienced some form of diversity) found the procedures positive. Implications for research and practice are presented.
\end{abstract}

The demographic composition of the United States is becoming increasingly diverse. Currently, 38\% of elementary school children are

The research described herein was supported by federal grants awarded to the first author by the U.S. Department of Education, Office of Special Education and Rehabilitative Services. The statements and opinions contained herein belong to the authors and are not reflective of the granting agency.

The authors would like to acknowledge the several parents, teachers, graduate students, and children who all contributed greatly to the completion of this study.

Address correspondence to the first author at University of Nebraska-Lincoln, Nebraska Center for Research on Children, Youth, Families, and Schools, 216 Mabel Lee Hall, Lincoln, NE 68588-0234; E-mail: ssheridan2@unl.edu. 
ethnic minorities, and it is likely that White Americans will cease to be the numerical majority between the years 2030 and 2050 (Sue, 1997). At the same time, one in six children in the United States is living in poverty and $28 \%$ are living with a single parent (Annie E. Casey Foundation, 2004). The proportion of American school children who were English Language Learners was 10.2\% in 2003 (National Clearinghouse for English Language Acquisition, 2004). Most importantly, the number of children who are diverse with respect to their socioeconomic status, language, or other characteristics is increasing rapidly (Lynch \& Hanson, 2004). Thus, it is more important than ever to examine the efficacy of services provided to diverse children in American schools.

Diversity is defined as demonstrating characteristics that are unique or different from the mainstream society, including those of ethnicity, socioeconomic status, parental educational level, language, and family stability, among others (Sue, Bingham, Porch-Burke, \& Vasquez, 1999). In the present study, diversity factors that were investigated included socioeconomic status (household income of less than $\$ 15,000$ ), family composition (fewer than two adults in the home), ethnicity (nonCaucasian), maternal education level (less than a high school education), and language spoken in the home (nonEnglish.) All of these diversity factors have been identified as predicting lower rates of school completion (Doll \& Hess, 2004; Rumberger \& Larson, 1998). Moreover, all five of the diversity factors investigated in this study have been identified as social differences that challenge attempts to build collaborative relationships across educators, parents, and communities (Giles, 2002). When values, life experiences, and expectations of diverse families differ in important ways from those of the educators who teach their children, communication and cooperation become more difficult to achieve (Sue et al., 1999).

A premise underlying this study is that the challenges posed by diversity do not represent deficits in the child, the school, or the family, but are evidence of a lack of synchrony within the child/family/school system (Pianta \& Walsh, 1996). Effective learning transitions will be better supported when students experience continuity across home and school (Christenson \& Sheridan, 2001). This premise is supported by a comprehensive ethnographic study of ethnically diverse adolescents in which students who experienced discontinuity across their home, school, and peer worlds had the most difficulty in making transitions among these different contexts and were at greatest risk for poor school performance and mental health concerns (Phelan, Davidson, \& Yu, 1998). Low-achieving students in the study reported extreme difficulty when the values, beliefs, knowledge, skills, and actions of their group were undervalued. In contrast, students moved easily and smoothly between 
and among home and school environments when they experienced congruent worlds, where similar values, expectations, and ways of behaving were evident among their family, school, and peers.

In this exploratory study, the cumulative effect of diversity was the variable of interest, and it was operationalized by the number of respects in which a child differed from the mainstream population. There is ample justification for this operationalization within the developmental risk research, where overwhelming evidence from multiple, independent longitudinal studies shows that the cumulative effect, and not simply the presence of isolated risk or diversity factors, makes students vulnerable to adverse outcomes (Bureau of the Census, 1996; Coie et al., 1993; Rutter \& Sroufe, 2000; Werner, 1989). As a recent example, the U. S. Bureau of the Census's 1996 population survey found a strong relationship between number of risk factors experienced by adolescent participants and outcomes such as school dropout, teenage pregnancy, and parenting (U. S. Department of Commerce, 1997). Given this precedent, we have used a similar strategy to represent the cumulative effects of diversity (i.e., the number of diversity characteristics).

Cross-system consultation provides multiple opportunities to minimize conflicting demands experienced by diverse students and build congruence between diverse families and schools. Incongruencies may be minimized and continuities enhanced when families and schools (a) communicate frequently; (b) discuss perspectives; (c) clarify roles, responsibilities and resources; and (d) make shared decisions (Christenson \& Sheridan, 2001; Comer, Haynes, Joyner, \& Ben-Avie, 1996). These actions allow educators to develop awareness of students' differences, allow more time to develop relationships and trust building with parents, and aid parents in their understanding of differences between the home and school and in their feelings of acceptance at school (Tarver Behring, Cabello, Kushida, \& Marguia, 2000). However, structured and systematic procedures for enhancing continuities and decreasing discrepancies among diverse contexts are not well researched.

Conjoint behavioral consultation (CBC; Sheridan, Kratochwill, \& Bergan, 1996) is uniquely suited to intervening with children whose individual/family diversity threatens their educational success, requiring enhanced continuity between home and school. CBC is an indirect model of service delivery in which parents, teachers, and a consultant work together to address the academic, social, or behavioral needs of a child. As an extension of within-system (i.e., parent-only or teacheronly) consultation, $\mathrm{CBC}$ combines perspectives and resources across multiple systems (home, school, and other support systems) to effect 
positive change in a child. Parents and teachers serve as joint consultees, and consultation is conducted with parents and teachers working together in a cooperative, constructive manner (Sheridan et al., 1996).

CBC was designed to promote a partnership model that creates opportunities for families and schools to work together around a common interest. In doing so, it builds upon and promotes the capabilities and strengths of both family members and school personnel. It emerged as a unique and distinct service delivery model as proponents of behavioral consultation became concerned with the lack of attention given to the ecological realities of children. From an ecological-behavioral perspective, the coordination and interconnectedness among primary systems (e.g., home and school) in a child's life promotes continuity (Bronfenbrenner, 1977) and provides a "safety net" conducive for children's healthy development (Christenson \& Sheridan, 2001).

In a 4-year investigation of the outcomes of CBC, Sheridan, Eagle, Cowan, and Mickelson (2001) reported average effect sizes of 1.08 and 1.11 when addressing a range of academic, social, and behavioral difficulties in home and school settings, respectively. Additional studies have documented positive outcomes (both objective and subjective) associated with CBC service delivery (Colton \& Sheridan, 1998; Sheridan, Kratochwill, \& Elliott, 1990; Weiner, Sheridan, \& Jenson, 1998). Recent reviews of evidence-based family intervention and parent consultation models identified $\mathrm{CBC}$ as one of the few models demonstrating adequate methodological rigor and positive outcomes to be considered "efficacious" (Guli, 2005).

Although CBC outcome, process, and acceptability research is increasing (e.g., Sheridan, 1997; Sheridan et al., 2001), the potential for understanding the effectiveness of $\mathrm{CBC}$ with diverse clients has not received attention. Indeed, empirical investigation of the effectiveness of all forms of consultation with diverse clients and families lags far behind other areas of consultation research (Ingraham, 2000). Similarly, developments in the area of evidence-based interventions (EBIs) have sorely neglected samples of diverse participants (Doyle, 1998; Kratochwill \& Stoiber, 2002). Attention to the effects of consultation and interventions for specific diverse groups of children has been encouraged by leaders in the EBI movement (e.g., APA Division 16/Society for the Study of School Psychology Task Force on EBIs), who recommend evaluation of treatments and computation of separate effect sizes for individuals demonstrating diversity (Evidence Based Intervention Task Force, 2003; Kratochwill \& Stoiber, 2002).

Conceptual discussions of CBC's use with diverse clients have begun to appear. Specifically, Sheridan (2000) defined multicultural CBC 
as "a home-school consultation relationship wherein important individual differences are present among two or more participants (i.e., parent, teacher, student, school psychologist-consultant) with respect to association with distinct cultural group(s) . . . includ[ing] sociodemographic (e.g., race, gender, national origin, class, language) as well as less tangible features of individuals (e.g., beliefs, attitudes, values) and schools (e.g., norms, customs)" (p. 345). Features of CBC such as interactive and collaborative problem solving; distributed decision making; appreciation for cultural values, perspectives, and norms; and relationship building are consonant with the principles of multicultural sensitivity. This is consistent with the conceptualization of "multicultural" as being "multivisional" in perspective, or extending one's ability to understand other people (Soriano, Soriano, \& Jimenez, 1994) and the belief that multiculturalism not only refers to the coexistence of diverse groups but also the ability to work effectively with diverse groups (Sue, 1998). Relational processes inherent within the CBC model may allow for the recognition and appreciation of individual cultural differences among consultants, consultees, and clients.

Virtually no research has been conducted that identifies the efficacy of home-school consultation services with a diverse sample. The present study begins to address this need by examining case studies conducted in applied settings over the course of 8 years.

\section{EXPLORATORY QUESTIONS}

Several exploratory questions were posed in this study. Specifically:

1. What are the effects of CBC across home and school settings when working with clients and families who represent varying levels of diversity?

2. To what degree do parents and teachers of clients representing varying levels of diversity find the $\mathrm{CBC}$ model acceptable?

3. To what degree do parents and teachers of clients representing varying levels of diversity report the outcomes to be effective?

4. To what degree do parents and teachers of clients representing varying levels of diversity report satisfaction with the consultant and services?

\section{METHODS}

The current study represents a subset of a larger, multiyear CBC study conducted in two locations. One setting was an urban western city, and the other was a suburban midwestern city with a high influx of immi- 
TABLE 1. Demographic Characteristics of Participants

\begin{tabular}{lrrr}
\hline & Child & Parent & Teacher \\
\hline Sample Size & 125 & 143 & 127 \\
Gender & & & \\
$\quad$ Males & 92 & 36 & 21 \\
Females & 33 & 107 & 106 \\
Average Age & 8.74 & 38.75 & 38.91 \\
SD & 3.36 & 8.44 & 9.57 \\
\% Diverse based on ${ }^{1}$ : & & & \\
Ethnicity & 23.2 & 13 & 5 \\
Income & 15.3 & 15.3 & $\mathrm{NA}^{2}$ \\
Number Adults in Home & 19.5 & 19.5 & $\mathrm{NA}$ \\
Maternal Education & 6.9 & 6.9 & $\mathrm{NA}$ \\
Language & 4.8 & 4.0 & $\mathrm{NA}$ \\
Level of Diversity & & & \\
0 & $72(57.6 \%)$ & & \\
1 & $33(26.4 \%)$ & & \\
2 or More & $20(16.0 \%)$ & & \\
\hline
\end{tabular}

Note. ${ }^{1}$ Data reflect the percent of clients in each sample that experienced each diversity characteristic. Diversity based on ethnicity included all non-Caucasian clients. Diversity based on income included clients whose family income was less that $\$ 15,000$ per year. Diversity based on number of adults in the home included clients who had fewer than one adult in the household. Diversity based on maternal education included clients whose mothers did nothave a high school diploma. Diversity based on language included clients who did not speak English in the home. ${ }^{2} \mathrm{NA}=$ Not applicable.

grants into the community. Funding was provided by the U.S. Department of Education via personnel preparation grants. Cases selected for the current subset included all cases that contained complete demographic, pre-consultation, and post-consultation data. The current sample represents $89 \%$ of the original sample. Numerous outcomes were assessed, including objective behavioral change and social validity (acceptability and subjective perceptions of efficacy).

The efficacy of CBC with diverse clients was explored by investigating case outcomes. Diversity in the present study was defined in sociodemographic terms (i.e., ethnicity, socioeconomic status, language spoken in the home, number of adults in the home, and maternal educational level; Natriello, McDill, \& Pallas, 1990). The primary variable of interest was the effect of cumulative diversity on the outcome variables, rather than mere presence of any single diversity factor. 
TABLE 2. Diversity Characteristics of Child Clients

\begin{tabular}{lcccc}
\hline & $\begin{array}{c}\text { Total } \\
\text { Sample } \\
(n=\mathbf{1 2 5})\end{array}$ & $\begin{array}{c}\text { Children with } \\
\text { One Diversity } \\
\text { Characteristic } \\
(n=33)\end{array}$ & $\begin{array}{c}\text { Children with } \\
\text { Two Diversity } \\
\text { Characteristics } \\
(n=13)\end{array}$ & $\begin{array}{c}\text { Children with } \\
\text { Three Diversity } \\
\text { Characteristics }\end{array}$ \\
Characteristic & $23.2 \%$ & $31.4 \%$ & $87.5 \%$ & $100 \%$ \\
\hline Ethnicity & $15.3 \%$ & $14.3 \%$ & $58.3 \%$ & $100 \%$ \\
Income & $19.5 \%$ & $42.9 \%$ & $45.8 \%$ & $50 \%$ \\
Adults in Home & $6.9 \%$ & $8.6 \%$ & $25.0 \%$ & $33 \%$ \\
Maternal Education & $4.8 \%$ & 0 & $33.3 \%$ & $17 \%$ \\
Language & &
\end{tabular}

\section{Participants}

Child-clients. Participants were 125 child-clients who ranged in age from 3 to 15 (mean $=8.74)$. Some clients were involved in more than one consultation, yielding a total of 135 cases. Seventy-four percent were male; $26 \%$ were female. The mean grade of clients was 3.5 $($ range $=$ preschool through grade 9$)$. Forty-seven percent of students had some form of disorder or disability (e.g., learning disability, behavioral disorder, attention-deficit hyperactivity disorder).

Demographic features of child participants are presented in Table 1 , and a description of the diversity of child participants is included in Table 2. Forty-four percent of the children were diverse in one or more respect. Collectively, $26 \%$ of the clients experienced one form of diversity; $18 \%$ demonstrated two or more. Of these, the most frequent diversity characteristic was family composition, followed by ethnicity. Approximately $23 \%$ of the sample were identified by their parents as racially diverse (nonWhite); $19.5 \%$ had only one adult living at home; $15.3 \%$ were living in poverty conditions; $6.9 \%$ had mothers who had not completed high school; and $4.8 \%$ spoke a language other than English in the home.

Parents. One hundred and forty three parents participated in this study. Of these, $75 \%$ were female; $25 \%$ were male. The mean age of parents was 38.75 years (range $=20-73$ years; $S D=8.44$ ). Seven percent had not completed high school; $53 \%$ had a high school diploma; 30\% 
had earned a bachelor's degree, and 10\% held a master's or doctorate. Of the parents, $87 \%$ were Caucasian and $15.3 \%$ were living in poverty.

Teachers. One hundred and six female and 21 male teachers were involved in the study. The mean age of teachers was 38.91 years (range $=21-58$ years; $S D=9.57$ ). Seventy nine percent of the teachers taught in general education classrooms; $10 \%$ were responsible for providing instruction in special education settings; and 10\% taught in preschool classrooms. Sixty-one percent of teachers had a bachelor's as their highest degree earned; $36 \%$ had a master's or doctorate. Of the teachers, 95\% were Caucasian.

Consultants. Consultants in the present study were 52 graduate students in school psychology programs in major western or midwestern universities. Eighty-five percent were female and $92 \%$ were Caucasian. The mean age of consultants was 27.86 years (range $=22-53$ years; $S D=$ 6.42). Fifty percent of consultants were in a doctoral program and had previously earned a master's degree. The remaining $50 \%$ were in a master's program and held a bachelor's degree at the time of the study. Consultants completed an average of 2.56 CBC cases (range $=1-9$ ) used in this study. Twenty-seven percent were involved in one case, 38\% participated in two cases, and 35\% were consultants in more than three cases.

\section{Setting}

This study took place in two states across two regions in the country (the intermountain west and the midwest). Cases were conducted in preschool, elementary, and middle school settings. The majority of CBC interviews were conducted in the classrooms of participating teachers; some were conducted in homes. Interventions were implemented in the homes and schools of students who were the focus of consultation.

\section{CBC Case Outcomes}

Several variables were measured to evaluate outcomes of CBC cases with diverse clients. The primary dependent variables were clients' behaviors or academic performance measured by direct observations or permanent products of target behaviors in naturalistic settings. Additionally, social validity of outcomes (i.e., subjective evaluation of outcomes, perceptions of goal attainment), and social validity of processes (i.e., subjective ratings of acceptability and satisfaction with $\mathrm{CBC}$ ) were collected for each case. Social validation is of particular interest with diverse clients and families. These latter variables were analyzed and reported descriptively. Multimethod, multisource, multisetting assess- 
ment procedures were used to evaluate the case outcomes. Procedures are presented below in relation to each outcome variable.

Behavior or Performance. Clients' behaviors or academic performance served as primary dependent variables, with direct observations or permanent performance products serving as the typical assessment method. Specific target behaviors were identified for each student at school and home. At school, $54 \%$ of the target behaviors were behavioral, $36 \%$ were academic, and $10 \%$ were social. At home, $58 \%, 30 \%$, and $12 \%$ were behavioral, academic, and social, respectively. Direct behavioral measures were collected continuously by parents and teachers throughout baseline, treatment, and follow-up phases. Thirty-three percent of the data were collected from permanent products of student performance such as worksheets or homework assignments. Sixty-seven percent were obtained from data collection forms that were provided to consultees to (a) standardize the observational procedures, (b) enhance training in data collection procedures, (c) increase reliability of data collection, and (d) provide a permanent record of student performance (Noell, in press).

Subjective Evaluation of $C B C$ Outcome. Consultees' subjective perceptions of case outcomes, one form of social validity, were assessed using a standardized Likert scale and Goal Attainment Scaling. Parents' and teachers' subjective beliefs of treatment efficacy were assessed on a revised version the Behavior Intervention Rating Scale (BIRS; Von Brock \& Elliott, 1987). Parents and teachers completed the revised BIRS in its entirety following final Conjoint Treatment Evaluation Interviews. The scale includes 24 items rated on a 6-point Likert scale. Perceptions of treatment efficacy were assessed using the revised Effectiveness factor, which is comprised of 7 items scored on a 6 -point Likert scale ( $1=$ low perceived efficacy; $6=$ high perceived efficacy). Minor revisions of the BIRS' original wording made the instrument applicable to consultation procedures, while still maintaining psychometric soundness.

Factor analysis of the BIRS has yielded three factors: Acceptability, Effectiveness, and Time to Effect (Elliott \& Von Brock Treuting, 1991). A study conducted by Von Brock and Elliott (1987) revealed alpha coefficients of .97 for the total scale and $.97, .92$, and .87 for the Acceptability, Effectiveness, and Time to Effect factors, respectively. Internal consistency of the revised BIRS total scale was derived from the sample utilized in a previous study conducted by Sheridan et al. (2001) and yielded alpha coefficients of $r=.95$ for teachers and $r=.93$ for parents.

A second form of subjective evaluation assessed parents' and teachers' perceptions of consultation goals. Goal Attainment Scaling (GAS; Kiresuk, Smith, \& Cardillo, 1994) procedures were used for this pur- 
pose. Following consultation, parents and teachers reported the degree to which they believed consultation goals were met using a scale of -2 (situation got significantly worse) to +2 (goal completely met). Sladeczek, Elliott, Kratochwill, Robertson-Mjaanes, and Stoiber (2001) demonstrated that GAS is a viable assessment methodology for evaluating CBC casework. Reviews of the reliability and validity of the GAS indicate interrater reliability indices between $r=.87$ (Kaplan \& Smith, 1994) and $r=.93$ (Schippits \& Baxter, 1978 as cited in Cardillo \& Smith, 1994). Test-retest reliability yielded correlations of $r=.84$ over a 2-to 3week period (Woodward, Santa-Barbara, Levin, \& Epstein, 1978). In addition, construct (e.g., Johnson \& Greenberg, 1985) and criterion-related validity (Jacobs \& Cytrynbaum, 1977) are also evident.

Ratings of CBC Acceptability. Parents' and teachers' acceptability of CBC (process acceptability) was assessed with the Acceptability factor of the revised BIRS. Fifteen items comprise the Acceptability factor, with items scored on a 6 -point Likert scale ( $1=$ not at all acceptable; 6 $=$ highly acceptable). Sheridan et al. (2001) reported alpha coefficients of $r=.94$ and .86 for parents and teachers, respectively, for the Acceptability factor revised for CBC.

Ratings of Satisfaction with CBC Services. The Consultant Evaluation Form (CEF; Erchul, 1987) was used to assess parents' and teachers' satisfaction with the consultant and CBC services. The CEF is a 12 item, 7-point Likert scale that measures the degree to which consultees find consultants helpful. Parents and teachers completed the CEF after final Treatment Evaluation Interviews. Early research yielded satisfactory internal consistency estimates (alpha $=.95$; Erchul, 1987). Alpha coefficients of $r=.83$ for parents and $r=.89$ for teachers were found for the Sheridan et al. (2001) sample.

\section{CBC Consultation Procedures}

Data from this study were derived from multiple years of federally funded training grants for which the first author was the principal investigator. Over the grant period, school psychology graduate students were trained to mastery in the principles and procedures of $C B C$ using competency-based training methods. Prior to initiating casework, students demonstrated mastery in CBC procedures, defined as meeting an average of $85 \%$ of CBC interview objectives. Further information on competency-based training procedures, structured interviews, and consultation casework are presented in Kratochwill, Sheridan, Rotto, and Salmon (1991) and Sheridan (1992).

Once graduate students were placed in school settings, referrals for $\mathrm{CBC}$ cases were solicited from school psychologists, administrators, 
and other school staff. The vast majority of cases that were initiated were completed; few resulted in premature termination. There are no data available on referrals that were declined by parents or teachers. For the majority of cases, consultants held pre-consultation meetings with parents and teachers prior to the problem identification stage. The purposes of these meetings included (a) initiating a relationship between the parent and teacher and between the consultant and consultees; (b) establishing a climate of collegiality, shared ownership, and home-school partnership; (c) obtaining background information; and (d) obtaining parental and teacher consent for participation, among other things (Sheridan et al., 2001).

Conjoint behavioral consultation cases followed a four-stage problem solving model, including conjoint problem identification, problem analysis, plan implementation, and plan evaluation (Sheridan et al., 1996). CBC consultation occurred with parents and teachers serving as co-consultees in the same meetings. The stages were initiated via structured interview procedures using formats available in the published literature (Sheridan et al., 1996). All cases were audiotaped for supervision and evaluation purposes.

\section{Integrity of CBC Process}

Process integrity was assessed in $93 \%$ of all cases, including all CBC interviews (i.e., PII, PAI, TEI). Of these 261 interviews, 26 (9.96\%) were either inaudible or missing from the dataset (some interviews were not audiotaped due to recorder malfunction or other unavoidable circumstances). Ninety-seven percent $(n=228)$ of the remaining 235 audiotaped interviews $(84.23 \%$ of the 261 available interviews) were coded by observers to assess the degree to which consultants followed CBC procedures with integrity. The mean level of process integrity for all coded CBC interviews was $88.93 \%(S D=9.68)$.

\section{Integrity of Interventions}

Treatment integrity of consultation-derived interventions across home and school was determined in one of two ways. First, evidence of treatment integrity was determined by reviewing aspects of behavioral programs that yielded permanent products (e.g., sticker charts, contracts, home notes, self-monitoring sheets; Noell, in press). Second, intervention plans were recorded on "Treatment Plan Worksheets." Specifically, the steps of interventions were listed on the worksheet upon which consultees self-recorded completion of the steps of the treatment plan. 


\section{Coding of Data}

Data from demographic information forms, final perceptions forms, behavioral records, treatment plan worksheets, and case reports were entered into a spreadsheet by three graduate research assistants trained by the first author. In addition, frequent checks for accuracy were made by the second author, with corrections made to the computerized dataset as necessary. At project termination, five graduate student observers checked data from $30 \%$ of the cases to assess interrater reliability. Across all codes, interrater reliability between the spreadsheet and the observers was $98.4 \%$, suggesting a high degree of accuracy in the CBC dataset.

\section{Design and Data Analysis}

Single-subject effect sizes were computed for each intervention outcome. Specifically, effect sizes for each case were computed using a "no assumptions" approach (Busk \& Serlin, 1992; Busse, Kratochwill, \& Elliott, 1995) that computes effects without assumptions regarding population distributions or homogeneity of variance. In this approach, the difference in baseline and treatment means within a given case is divided by the standard deviation of the baseline, which produces a quantitative index of treatment effects. Some cases had interventions that yielded effect sizes in both home and school settings giving rise to two single-subject effect sizes for those cases. A total of 192 single-subject effect sizes are included in the dataset. Eighty-one are effect sizes for home-based interventions, and 111 are effect sizes for school interventions. According to Cohen (1992), an effect size of .2 is considered small, an effect size of .5 is medium, and an effect size of .8 is large.

To further understand the aggregate results, $95 \%$ confidence intervals were computed for the average effect sizes. Confidence intervals present a range of values within which "true" average effect size is likely to lie (Kirk, 1996). The upper and lower limits of the interval provide information of the magnitude of the difference. The difference between the upper and lower limits of the interval index the precision with which the mean effect sizes have been estimated. The more narrow the interval, the more precise the estimate.

Limitations imposed by the composition of the sample presented restrictions on the types of analyses possible with this dataset. Specifically, overlap among diversity groups was evident, resulting in lack of independence across groups. Likewise, for some diversity groups, the sample size was very small (e.g., participants who spoke a language other than English or whose mother had less than a high school education). Furthermore, given the exploratory nature of this study, statistical 
TABLE 3. Effect Sizes Setting and Level of Diversity

\begin{tabular}{|c|c|c|c|c|c|}
\hline & $n$ & Mean & Median & $\begin{array}{l}\text { Standard } \\
\text { Deviation }\end{array}$ & $\begin{array}{r}95 \% \\
\text { Confidence } \\
\text { Interval }\end{array}$ \\
\hline \multicolumn{6}{|c|}{ School Effect Sizes } \\
\hline Diversity $=0$ & 58 & 1.12 & 0.74 & 1.64 & $0.69-1.55$ \\
\hline Diversity $=1$ & 33 & 1.25 & 1.19 & 1.41 & $0.75-1.75$ \\
\hline Diversity $\geq 2$ & 20 & 1.38 & 1.20 & 1.21 & $0.65-2.11$ \\
\hline \multicolumn{6}{|c|}{ Home Effect Sizes } \\
\hline Diversity $=0$ & 44 & 1.74 & 1.21 & 2.52 & $0.7-2.51$ \\
\hline Diversity $=1$ & 20 & 1.07 & 1.06 & 1.15 & $0.53-1.61$ \\
\hline Diversity $\geq 2$ & 17 & 1.45 & 1.13 & 1.82 & $0.52-2.39$ \\
\hline \multicolumn{6}{|c|}{ Overall Effect Sizes ${ }^{1}$} \\
\hline Diversity $=0$ & 76 & 1.35 & 1.05 & 2.18 & $0.85-1.85$ \\
\hline Diversity $=1$ & 35 & 1.21 & 1.08 & 1.12 & $0.83-1.60$ \\
\hline Diversity $>2$ & 24 & 1.51 & 1.28 & 1.52 & $0.87-2.15$ \\
\hline
\end{tabular}

Note. ${ }^{1}$ Overall effect size reflects the number of cases for which effect sizes are available within each group.

hypothesis testing was considered premature at this time. Our concern was whether CBC produced an effect and if so, the magnitude of that effect, rather than whether there were differences in outcomes across diverse groups. Effect sizes provide information about the importance of a difference or relationship, and on the magnitude of results in relation to sample size and error. They have been suggested by some as more informative than knowledge that a statistical test is significant (Carver, 1978; Chow, 1988; Levin, 1998; Robinson \& Levin, 1997).

\section{RESULTS}

Table 3 and Figure 1 present the effect sizes and confidence intervals across school and home settings for clients who represent 0,1 , and 2 or more forms of diversity. Because the data are highly variable, as evidenced by standard deviations over 1.0, both mean and median effect sizes are presented. Overall, the average effect size for students with no diversity factors was 1.35 (median $=1.05 ; S D=2.18$ ). When students experienced one form of diversity, the average effect size was 1.21 (median $=1.08 ; S D=1.12$ ). When two or more dimensions of diversity were present, the average effect size was 1.51 (median $=1.28$; $S D=1.52$ ). All mean effect sizes are high based on Cohen's (1992) criteria that an effect size of .2 is considered small, an effect size of .5 is medium, and an effect size of .8 is large. 


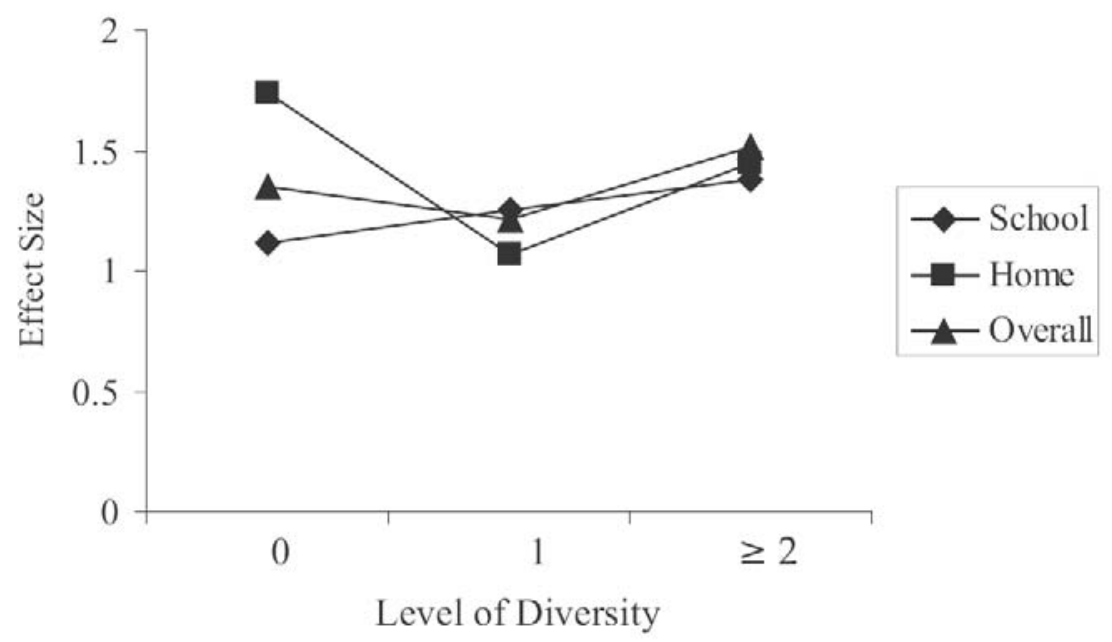

FIGURE 1. Mean effect sizes by level of diversity.

Across all cases and diversity levels, the confidence interval on effect sizes was .83-2.15, suggesting that the "true" average effect size related to $\mathrm{CBC}$ across diversity levels is contained within this range with $95 \%$ confidence. As can be seen in Table 3, effect sizes within the confidence intervals are all positive. The most precise interval range was found for students experiencing one form of diversity (i.e., difference between upper and lower limit of range $=.77$ ); the least precise interval range was for students experiencing two or more forms of diversity (i.e., difference between upper and lower limits $=1.28$ ).

\section{Parent and Teacher Perceptions of Effectiveness of CBC}

Parents' and teachers' ratings of the effectiveness of $\mathrm{CBC}$ were measured using the BIRS-Revised Effectiveness factor. The results are in Table 4. Parents and teachers uniformly rated CBC as somewhat to moderately effective at addressing the presenting concerns. Parents routinely rated the procedures as more effective than did teachers, and these ratings increased as levels of diversity increased.

Table 4 also presents the results of Goal Attainment Scaling that was used as a second measure of perceptions of outcomes. Rated on a scale of 1-5 (with 5 representing the belief that the consultation goal was completely met), parents' and teachers' ratings reflected positive out- 
TABLE 4. Effectiveness, Acceptability, and Satisfaction Ratings of Parents and Teachers across Levels of Diversity

\begin{tabular}{lrrr}
\hline & Diversity $=0$ & Diversity $=1$ & Diversity $\geq 2$ \\
\hline $\begin{array}{l}\text { BIRS-Eff } \\
\text { Parent }\end{array}$ & $4.36(1.11)$ & $4.57(1.06)$ & $4.99(.80)$ \\
Teacher & $3.98(1.20)$ & $3.95(1.27)$ & $4.70(0.74)$ \\
GAS $^{2}$ & & & \\
Parent & $4.40(.58)$ & $4.29(.62)$ & $4.41(.51)$ \\
Teacher & $4.19(.80)$ & $4.17(.70)$ & $4.5(.51)$ \\
BIRS-Acc & & & \\
Parent & $5.36(.54)$ & $5.29(.63)$ & $5.48(.55)$ \\
Teacher & $5.22(.74)$ & $5.28(.73)$ & $5.53(.57)$ \\
CEF & & & \\
Parent & $6.15(.87)$ & $6.22(.62)$ & $6.52(.61)$ \\
Teacher & $6.21(.72)$ & $6.27(.79)$ & $6.54(.58)$ \\
\hline
\end{tabular}

Note. ${ }^{1}$ BIRS-Eff: Average item ratings for parents and teachers on the Behavior Intervention Rating Scale (Revised) - Effectiveness factor. Possible scores range from 1-6 $(1=$ not at all effective; $6=$ highly effective). Numbers in parentheses represent standard deviations. ${ }^{2}$ GAS: Average ratings on Goal Attainment Scaling. Possible scores range from $1-5(1=$ goal not met; situation significantly worse to $5=$ goal completely met). Numbers in parentheses represent standard deviations. BIRS-Acc: Average item ratings for parents and teachers on the Behavior Intervention Rating Scale (Revised) - Acceptability factor. Possible scores range from $1-6(1=$ not at all acceptable; $6=$ highly acceptable). Numbers in parentheses represent standard deviations. ${ }^{4} \mathrm{CEF}$ : Average item ratings for parents and teachers on the Consultant Evaluation Form. Possible scores range from 1-7 $(1=$ not at all satisfied; $7=$ highly satisfied). Numbers in parentheses represent standard deviations.

comes across groups. Again, parents generally rated goal attainment more positively than teachers, with few differences across groups representing different levels of diversity. Within parent ratings and teacher ratings, the highest levels of goal attainment were achieved with the most diverse group.

\section{Parent and Teacher Acceptability of CBC}

Ratings of parents' and teachers' acceptability of $\mathrm{CBC}$ also are presented in Table 4. Parents and teachers uniformly rated the CBC procedures as very to highly acceptable. Parents and teachers rated the acceptability of $\mathrm{CBC}$ in a very similar fashion, with the highest ratings for groups representing the greatest levels of diversity. 


\section{Parent and Teacher Satisfaction with CBC Services}

Mean ratings of parent and teacher satisfaction with $\mathrm{CBC}$ services are in Table 4. Parents and teachers uniformly reported very high levels of satisfaction with $C B C$ and the consultant. In this case, ratings made by teachers were higher than those by parents, and for both respondents, satisfaction increased as diversity increased.

\section{DISCUSSION}

In an article that provided the initial theoretical framework for multicultural CBC, Sheridan (2000) identified the need for empirical investigation of $\mathrm{CBC}$ with diverse clients. This is the first study to investigate the efficacy of $\mathrm{CBC}$ with diverse clients. The purpose of this study was to explore the effects of $\mathrm{CBC}$ based on the cumulative effects of diversity characteristics, not to analyze whether $\mathrm{CBC}$ was more effective based on the type of diversity. Both objective accounts of behavioral change and perceptions of parents and teachers were investigated. Generally positive behavioral outcomes were found for students regardless of the presence and number of diversity indicators, including ethnicity, socioeconomic status, family composition, maternal education, or language spoken in the home. It appears that the variability in CBC outcomes was based on factors other than the number of diversity characteristics. These results corroborate previous research that suggests that demographic variables fail to predict parental involvement and related positive student outcomes (Walberg, 1984; White, 1982).

Tarver Behring et al. (2000) called for further evaluation of collaboration between consultees and consultants of different backgrounds within consultative models. Specifically, the authors cited perspectives that (a) discussion and sharing of ideas, essential to collaboration, may be inhibited when working with diverse consultees (Tarver Behring \& Gelinas, 1996) and (b) collaboration with consultees of minority or low SES backgrounds may not be realistic due to perceived differences of one's position in a culturally dominant society (Ramirez, Lepage, Kratochwill, \& Duffy, 1998). Results from this study suggest that consultees from a variety of diverse backgrounds are able to effectively participate in a collaborative consultation model, such as CBC.

It is not known whether $\mathrm{CBC}$ actually facilitated cross-systemic continuity, thereby affecting case outcomes, or if other structural or relational features of the model contributed to positive outcomes. Tarver Behring et al. (2000) found that consultants working in cross-cultural situations recommended modifications such as helping teachers develop awareness of students' cultural differences, allowing more time to develop re- 
lationships and trust building with parents, and aiding parents in their understanding of differences between the home and school cultures and their feelings of acceptance at school. Indeed, inherent in the process of CBC are principles and objectives related to fostering culturally sensitive services, including (a) helping teachers develop an awareness of students' differences, (b) taking time to establish and foster effective homeschool relationships, (c) assisting parents to understand differences and similarities among themselves and the larger school culture, (d) building trust among parties, and (e) developing shared commitments to student success (Sheridan, 2000; Tarver Behring et al., 2000). It is possible that strategies used by consultants to meet these general CBC objectives (Sheridan et al., 1996) also support objectives necessary to be effective in multicultural consultation (Sheridan, 2000).

Given the lack of experimental control implicit in the case studies, the lack of random selection and assignment, and limited sample size within each diversity group, the present findings must be considered with caution. Additionally, given that the project focused on training graduate students in the effective implementation of $\mathrm{CBC}$, reliability assessments of direct behavioral observations were not collected. Although these are important research limitations, the strategies discussed herein represent naturalistic problem solving consultation cases, and followed a "best practices" approach to data-based decision making. Our current approach to field research included multiple elements that allowed us to draw meaningful inferences from our case data (Galloway \& Sheridan, 1994; Kratochwill, 1985). However, research is needed that uses more highly controlled procedures and independent observers in data collection. Likewise, large-scale research projects should investigate procedures for monitoring behavior over time using repeated measures that are sensitive, reliable, and field-based.

A second and related limitation of this study is the lack of systematic objective measures of treatment integrity. Researchers have suggested that the generalization of consultation recommendations to consultees' actions be assessed in applied studies (cf. Noell, Gresham, \& Gansle, 2002). Research is needed to assess consultees' skills at implementing interventions within consultation programs and the relations between these consultee skills and consultation outcomes.

Third, diversity indicators in this study were based on parental reports. No objective means were used to determine socioeconomic status, ethnicity, or other diversity variables. Related to this is the dichotomization of variables to indicate diversity. Indeed, given the small number of children with certain diversity characteristics, it was not possible to examine the relative meaning of each characteristic. Fur- 
ther, it is possible that the diversity sample failed to include individuals who may have appropriately represented diversity if it had been operationalized in more sensitive ways. For example, recent census data may be used to redefine the groups and better reflect current population estimates. Alternatively, developmental research could be used as a basis to select the diversity variables that appear most relevant to individual differences in child competence.

Large-scale research is sorely needed exploring these patterns in a more rigorous manner. Specifically, research is needed using rigorous designs that control for threats to internal validity, including clarification of the participant group, random selection and assignment to treatment and control conditions, comparisons to matched control groups, attention to the nested nature of intervention sites, and systematic attention to intervention fidelity, to name a few. In addition, mixed-method designs that include features of qualitative methodology would be extremely valuable in exploring many dynamics related to working with diverse families and children.

The present study suggests that positive outcomes are possible within consultation when working with diverse families and clients. Although other researchers (Rogers, 1998; Tarver-Behring et al., 1996) have suggested the need to address multicultural issues directly and explicitly in consultation, it is possible that CBC consultants in the present study incorporated strategies into their practice that indirectly addressed diversity effectively. It is possible that relational practices inherent within the $\mathrm{CBC}$ model allowed for the recognition of individual differences of consultees and clients and created greater synchrony among the child's caretaking system (Sheridan, 2000).

\section{References}

Annie E. Casey Foundation (2004). KidsCount 2004 databook online. [Online]. Available on June 25, 2005 at http://www.aecf.org/kidscount/databook .

Bronfenbrenner, U. (1977). Toward an experimental ecology of human development. American Psychologist, 32, 513-529.

Busk, P. L., \& Serlin, R. C. (1992). Meta-analysis for single-case research. In T. R. Kratochwill \& J. R. Levin (Eds.), Single-case research design and analysis: Applications in psychology and education (pp. 187-212). Hillsdale, NJ: Lawrence Erlbaum Associates.

Busse, R. T., Kratochwill, T. R., \& Elliott, S. N. (1995). Meta-analysis for single-case consultation outcomes: Applications to research and practice. Journal of School Psychology, 33, 269-285.

Carver, R. P. (1978). The case against statistical significance testing. Harvard Educational Review, 48, 378-399.

Chow, S. L. (1988). Significance test or effect size? Psychological Bulletin, 103, 105-110. 
Christenson, S. L., \& Sheridan, S. M. (2001). Schools and families: Creating essential connections for learning. New York: The Guilford Press.

Cohen, J. (1992). A power primer. Psychological Bulletin, 112, 155-159.

Coie, J. D., Watt, N. F., West, S. G., Hawkins, J. D., Asarnow, J. R., Markan, H. J., Ramey, S. L., Shure, M., \& Long, B. (1993). The science of prevention: A conceptual framework and some directions for a national research program. American Psychologist, $48,1013-1022$.

Colton, D., \& Sheridan, S. M. (1998). Conjoint behavioral consultation and social skills training: Enhancing the play behavior of boys with attention deficit-hyperactivity disorder. Journal of Educational and Psychological Consultation, 9, 3-28.

Comer, J. P., Haynes, N. M., Joyner, E. T., \& Ben-Avie, M. (1996). Rallying the whole village: The Comer process for reforming education. New York: Teachers College Press.

Doll, B., \& Hess, R. (2004.) Interventions for children who drop out of school. In L. A. Rapp-Paglicci, C. N. Dulmus, \& J. S. Wodarski (Eds.), Handbook of prevention interventions for children and adolescents (pp. 359-380). Hoboken, NJ: John Wiley \& Sons.

Doyle, A. B. (1998). Are empirically validated treatments valid for culturally diverse populations? In K. S. Dobson \& K. D. Craig (Eds.), Empirically supported therapies: Best practice in professional psychology (pp. 93-103). Thousand Oaks, CA: Sage Publications.

Evidence Based Intervention Task Force (2003). Procedural and coding manual for review of evidence-based interventions. Madison, WI: Author.

Elliott, S. N., \& Von Brock Treuting, M. (1991). The Behavior Intervention Rating Scale: Development and validation of a pretreatment acceptability and effectiveness measure. Journal of School Psychology, 29, 43-51.

Erchul, W. P. (1987). A relational communication analysis of control in school consultation. Professional School Psychology, 2, 113-124.

Galloway, J., \& Sheridan, S. M. (1994). Implementing scientific practices through case studies: Examples using home-school interventions and consultation. Journal of School Psychology, 32, 385-413.

Giles, H. C. (2002). Transforming the deficit narrative: Race, class and social capital in parent-school relations. In C. Korn \& A. Bursztyn (Eds.), Rethinking multicultural education: Case studies in cultural transition (pp. 130-159).Westport, CT: Bergin \& Garvey.

Guli, L. (2005). Evidence-based parent consultation with school-related outcomes. School Psychology Quarterly, 20, 455-472.

Ingraham, C. L. (2000). Consultation through a multicultural lens: Multicultural and cross-cultural consultation in schools. School Psychology Review, 29, 320-343.

Jacobs, S., \& Cytrynbaum, S. (1977). The goal attainment scale: A test of its use on an inpatient crisis intervention unit. Goal Attainment Review, 3, 77-98.

Johnson, S. M., \& Greenberg, L. S. (1985). Differential effects of experiential and problem-solving interventions in resolving marital conflict, Journal of Consulting and Clinical Psychology, 53, 175-184

Kiresuk, T. J., Smith, A., \& Cardillo, J. E. (1994). Goal Attainment Scaling: Applications, theory, and measurement. Hillsdale, NJ: Erlbaum.

Kirk, R. E. (1996). Practical significance: A concept whose time has come. Educational and Psychological Measurement, 56, 746-759. 
Kratochwill, T. R. (1985). Case study research in school psychology. School Psychology Review, 14, 204-215.

Kratochwill, T. R., Sheridan, S. M., Rotto, P., \& Salmon, D. (1991). Preparation of school psychologists to serve as consultants for teachers of emotionally disturbed children. School Psychology Review, 20, 530-549.

Kratochwill, T. R., \& Stoiber, K. C. (2002). Evidence-based interventions in school psychology: Conceptual foundations of the procedural and coding manual of Division 16 and the Society for School Psychology Task Force. School Psychology Quarterly, 17, 341-389.

Levin, J. R. (1998). To test or not to test $H_{0}$ ? Educational and Psychological Measurement, 58, 313-333.

Lynch, E. W., \& Hanson, M. J. (Eds.). (2004). Developing a cross-cultural competence: A guide for working with children and their families (3rd ed.). Baltimore: Brookes.

National Clearinghouse for English Language Acquisition. (2004). Survey of the states. Online @ http://www.ncela.gwu.edu/policy/states/report/statedata Accessed June 25, 2005.

Natriello, G., McDill, E. L., \& Pallas, A. M. (1990). Schooling disadvantaged children: Racing against catastrophe. New York: Teachers College Press.

Noell, G. H. (in press). Research examining the relationships among consultation process, treatment integrity, and outcomes. In W. P. Erchul \& S. M. Sheridan (Eds.), Handbook of research in school consultation: Empirical foundations for the field. Hillsdale, NJ: Erlbaum.

Noell, G. H., Gresham, F. M., \& Gansle, K. A. (2002). Does treatment integrity matter? A preliminary investigation of instructional implementation and mathematics performance. Journal of Behavioral Education, 11, 51-67.

Phelan, P., Davidson, A. L., \& Yu, H. C. (1998). Adolescents' worlds: Negotiating family, peers, and school. New York: Teachers College Press.

Pianta, R. C., \& Walsh, D. J. (1996). High-risk children in schools: Constructing sustaining relationships. New York: Routledge.

Ramirez, S., Lepage, K. M., Kratochwill, T. R., \& Duffy, J. (1998). Multicultural issues in school-based consultation: Conceptual and research considerations. Journal of School Psychology, 36, 479-509.

Robinson, D. H., \& Levin, J. R. (1997). Reflections on statistical and substantive significance, with a slice of replication. Educational Researcher, 26, 21-26.

Rogers, M. R. (1998). The influence of race and consultant verbal behavior on perceptions of consultant competence and multicultural sensitivity. School Psychology Quarterly, 13, 265-280.

Rumberger, R. W., \& Larson, K. A. (1998). Student mobility and the increased risk of high school dropout. American Journal of Education, 107, 1-35.

Rutter, M., \& Sroufe, L. A. (2000). Developmental psychopathology: Concepts and challenges. Development and Psychopathology, 12, 265-296.

Sheridan, S. M. (2000). Considerations of multiculturalism and diversity in behavioral consultation with parents and teachers. School Psychology Review, 29, 344-353.

Sheridan, S. M. (1997). Conceptual and empirical bases of conjoint behavioral consultation. School Psychology Quarterly, 12, 119-133. 
Sheridan, S. M. (1992). Consultant and client outcomes of competency-based behavioral consultation training. School Psychology Quarterly, 7, 245-270.

Sheridan, S. M., Eagle, J. W., Cowan, R. J., \& Mickelson, W. (2001). The effects of conjoint behavioral consultation: Results of a four-year investigation. Journal of School Psychology, 39, 361-385.

Sheridan, S. M., Kratochwill, T. R., \& Bergan, J. R. (1996). Conjoint behavioral consultation: A procedural manual. New York: Plenum.

Sheridan, S. M., Kratochwill, T. R., \& Elliott, S. N. (1990). Behavioral consultation with parents and teachers: Delivering treatment for socially withdrawn children at home and school. School Psychology Review, 19, 33-52.

Sladeczek, I. E., Elliott, S. N., Kratochwill, T. R., Robertson-Mjaanes, S., \& Stoiber, K. C. (2001). Application of Goal Attainment Scaling to a conjoint behavioral consultation case. Journal of Educational \& Psychological Consultation, 21, 45-48.

Soriano, M., Soriano, F. I., \& Jimenez, E. (1994). School violence among culturally diverse populations: Sociocultural and institutional considerations. School Psychology Review, 23, 216-235.

Sue, D. W. (1997). Multiculturalism and discomfort. Spectrum, 57, 7-9. Sue, S. (1998). In search of cultural competence in psychotherapy and counseling. American Psychologist, 53, 440-448.

Sue, D. W., Bingham, R. P., Porch-Burke, L., \& Vasquez, M. (1999). The diversification of psychology: A multicultural revolution. American Psychologist, 54, 1061-1069.

Tarver Behring, S. T., Cabello, B., Kushida, D., \& Marguia, A. (2000). Cultural modifications to current school-based consultation approaches reported by culturally diverse beginning consultants. School Psychology Review, 29, 354-367.

Tarver Behring, S. T., \& Gelinas, R. T. (1996). School consultation with Asian American children and families. The California School Psychologist, 1, 13-20.

U.S. Department of Commerce (1997). Census brief: America's children at risk. Washington DC, U.S. Department of Commerce.

Von Brock, M. B., \& Elliott, S. N. (1987). Influence of treatment effectiveness information on the acceptability of classroom interventions. Journal of School Psychology, 25, 131-144.

Walberg, H. (1984). Families as partners in educational productivity. Phi Delta Kappan, $65,397-400$.

Weiner, R. K., Sheridan, S. M., \& Jenson, W. R. (1998). The effects of conjoint behavioral consultation and a structured homework program on math completion and accuracy in junior high students. School Psychology Quarterly, 13, 281-309.

Werner, E. E. (1989). High-risk children in young adulthood: A longitudinal study from birth to 32 years. American Journal of Orthopsychiatry, 59, 72-81.

White, K. R. (1982). The relationship between socioeconomic status and academic achievement. Psychological Bulletin, 91, 461-481.

Woodward, C. A., Santa-Barbara, J., Leven, S., \& Epstein, N. (1978). The role of Goal Attainment Scaling in evaluation family therapy outcome. American Journal of Orthopsychiatry, 48, 464-476. 
Susan M. Sheridan, Ph.D., is a Willa Cather Professor and Professor of Educational Psychology at the University of Nebraska-Lincoln. Her primary research interests are in the areas of conjoint behavioral consultation, homeschool partnerships, family engagement, and early intervention for children at risk. Dr. Sheridan is a past Lightner Witmer Award recipient and a Fellow of Division 16. She received her doctorate from the University of WisconsinMadison in 1989. The Ph.D. School Psychology Program at the University of Nebraska-Lincoln is accredited by the APA.

John W. Eagle, Ph.D., is an Assistant Professor in the School Psychology Program at the University of Kansas. His research interests include conjoint behavioral consultation, home-school community partnerships, parental involvement in schools, and prereferral interventions. Dr. Eagle received his degree from the University of Nebraska-Lincoln. The Ph.D. School Psychology Program at the University of Kansas is accredited by the APA.

Beth Doll, Ph.D., is a Professor in the School Psychology Program at the University of Nebraska Lincoln. Her research addresses models of school mental health that foster resilience and enhance the well-being of students in naturally-occurring communities, and secondarily, program evaluation strategies that demonstrate impact and accountability of school mental health services. Her publications on issues of resilience, school mental health, self-determination, the identification of emotional disabilities, and students' friendships appear in prominent national journals. The Ph.D. School Psychology Program at the University of Nebraska-Lincoln is accredited by the APA. 